\title{
Jogos africanos na formação de professores: o yoté como um recurso para o ensino de matemática
}

African games in teacher training: the yoté as a resource for mathematics teaching

\author{
Maria Gabriela de Figueiredo Furtado* \\ Paulo Gonçalo Farias Gonçalves**
}

\section{Resumo}

O baixo rendimento em Matemática e a inserção da cultura afro-brasileira no currículo tem sido um desafio para a formação docente. Assim, discute-se uma experiência educacional com o yoté no ensino de Geometria no âmbito de uma licenciatura em ciências naturais e matemática. Baseando-se em recomendações dadas por documentos oficiais (BRASIL, 1998, 2004, 2008, 2010) e em pesquisas de Educação Matemática sobre o uso de jogos (MULLER, 2014; GRANDO, 2015; BARRETO, 2016), esse estudo se constituiu como uma intervenção pedagógica e utilizou-se da observação e do questionário para recolha dos dados. Foi unânime entre os licenciandos a compreensão dos jogos como recursos promissores para o ensino e aprendizagem de matemática, sobretudo pelo seu aspecto lúdico, dinâmico, caráter facilitador; e no desenvolvimento de competências, habilidades e atitudes. Em relação ao yoté, foi destacada a importância da interação entre conceitos matemáticos e histórico-culturais. Dentre as desvantagens, os estudantes apresentaram a possibilidade de surgimento de comportamentos inadequados e a utilização do jogo pelo jogo. É fundamental que os cursos de licenciaturas empreendam práticas direcionadas não apenas aos conteúdos conceituais e procedimentais, mas ainda aos conteúdos atitudinais, essenciais para a formação de cidadãos que respeitem a diversidade e diferenças em uma sociedade multicultural.

Palavras-chave: Ensino e aprendizagem. Educação Matemática. Jogo africano.

\section{Introdução}

O baixo nível de aprendizagem dos estudantes brasileiros em Matemática tem se colocado como um grande percalço para educação escolar no país. Segundo resultados do Programa Internacional de Avaliação de Estudantes

\footnotetext{
* Discente do curso de Licenciatura Interdisciplinar em Ciências Naturais e Matemática da Universidade Federal do Cariri, campus Brejo Santo-CE. Email: gabyfigueiredo864@gmail.com.

** Professor da Universidade Federal do Cariri. Licenciado em Matemática, Mestre em Ensino de Ciências Naturais e Matemática e Doutorando em Educação. Email: paulo.goncalo@ufca.edu.br.
} 
(PISA, sigla em inglês), 70,25\% dos estudantes encontram-se em níveis inferiores aos considerados adequados ${ }^{1}$ pelo Exame (BRASIL, 2016).

Além dos conceitos matemáticos, é emergente ainda a inserção de práticas pedagógicas que estimulem a formação de atitudes. Um exemplo disso é a obrigatoriedade em todo currículo do Ensino Fundamental e Ensino Médio do estudo da cultura afro-brasileira e indígena (BRASIL, 2008). Isso requer um esforço mútuo de docentes das diversas disciplinas escolares (entre elas a matemática) para trabalharem juntos com os aspectos histórico-culturais, atitudes como reconhecimento e valorização de elementos afro-brasileiros e indígenas na constituição da cultura do Brasil.

O quadro desenhado até aqui traz um enorme desafio para os cursos de formação de professores, que precisam oportunizar ao futuro docente acesso a um rol de estratégias de ensino que o auxiliem a lidar com os desafios que se colocam na aprendizagem de conceitos e atitudes na disciplina de Matemática.

Dentre as diversas possibilidades discutidas no âmbito do campo da Educação Matemática, por ser um elemento encontrado em diversas culturas, ser potencialmente lúdico e possibilitar adaptações como um recurso didático para o contexto escolar, o jogo coloca-se como um elemento promissor para o processo de ensino e aprendizagem de matemática (FIORENTINI, MIORIM, 1990; GRANDO, 2015; BARRETO, 2016).

Nesse viés, o presente trabalho tem 0 intuito de apresentar uma experiência educacional com o jogo africano yoté, que teve como enfoque os conteúdos áreas e perímetros e a discussão de ícones da história afro-brasileira, ocorrida com alunos do curso de Licenciatura Interdisciplinar em Ciências Naturais e Matemática, da Universidade Federal do Cariri.

\section{Jogos africanos no ensino de Matemática}

${ }^{1}$ Em relação a matemática, o PISA classifica os estudantes em 7 níveis crescentes de proficiência (abaixo de 1, 1, 2, 3, 4, 5 e 6), considerando adequados o domínio de conhecimentos e habilidades matemáticas para o exercício da cidadania do nível 2 em diante. 
Consistindo em uma atividade recreativa entre uma ou mais pessoas realizada a partir de algumas regras pré-definidas, o jogo tem como um de seus enfoques principais o entretenimento. Podendo adquirir finalidades pedagógicas, ele pode se constituir como um recurso para a aprendizagem escolar.

A utilização do jogo como um recurso didático para o ensino de matemática coloca-se como uma estratégia promissora na proposição de problemas. Conforme Brasil (1998, p.46), os jogos possibilitam que problemas:

[...] sejam apresentados de modo atrativo e favoreçam a criatividade na elaboração de estratégias de resolução e busca de soluções. Propiciam a simulação de situações-problema que exigem soluções vivas e imediatas, o que estimula o planejamento das ações; possibilitam a construção de uma atitude positiva perante os erros, uma vez que as situações sucedem-se rapidamente e podem ser corrigidas de forma natural, no decorrer da ação, sem deixar marcas negativas (BRASIL, 1998, p. 46).

Nesse sentido, relacionar o aspecto lúdico intrínseco aos jogos com o processo de resolução de problemas contribui com a formação de atitudes essenciais ao pensamento matemático, como: enfretamento de desafios, busca por soluções, exercício da crítica e da intuição, (re)elaboração de estratégias, entre outras (BRASIL, 1998).

Segundo Grando (2015), o ato de jogar desencadeia procedimentos similares aos de resolver problemas, porém imerso num ambiente dinâmico. Para a autora,

O cerne da resolução de problemas está no processo de elaboração de estratégias, levantamento de hipóteses, problematização, registro e análise/validação de resoluções. No jogo ocorre fato semelhante. Ele representa uma situação-problema determinada por regras, em que o indivíduo busca a todo o momento, elaborando estratégias, procedimentos e reestruturando-os, vencer o jogo, ou seja, resolver o problema. Esse dinamismo característico do jogo é o que possibilita identificá-lo no contexto da resolução de problemas (GRANDO, 2015, p. 399).

Assim, os jogos com pouca dependência do fator sorte e que exigem a criação de estratégias para aumentar as chances de êxito do jogador (denominados jogos de estratégia), se colocam como meios para o exercício da 
resolução de problemas no processo de ensino e aprendizagem de matemática.

Encontrados em diversas civilizações africanas, os jogos de estratégia carregam elementos da história e da cultura dessas sociedades. Adaptados como recursos didáticos para o ensino de matemática, podem possibilitar uma experiência em sala de aula que agregue aspectos culturais e matemáticos, propiciando um ensino diversificado e a valorização da cultura Africana e Afrobrasileira. Conforme Barreto (2016, p.40), o uso dos jogos africanos no ensino de matemática, favorece o aprimoramento do raciocínio lógico-matemático e estimula:

[...] o diálogo (profícuo e profundo) dos alunos com aspectos da cultura africana, possibilitando uma ampliação de seus horizontes, uma vez que o contato com a cultura africana através dos jogos educativos africanos pode modificar a visão muitas vezes preconceituosa sobre o Continente Africano e de seus descendentes.

Esse trabalho conjunto entre aspectos conceituais e atitudinais no processo de ensino de matemática contribui para uma formação dos discentes preocupada não apenas com o domínio de conteúdos específicos, mas ainda com o exercício da valorização cultural, ambos, elementos essenciais para a cidadania.

A preocupação com um processo de ensino que insira aspectos da cultura afro-brasileira e africana por todos os estudantes do país é de suma importância, "[...] uma vez que devem educar-se enquanto cidadãos atuantes no seio de uma sociedade multicultural e pluriétnica, capazes de construir uma nação democrática" (BRASIL, 2004, p.17).

Dentre os diversos jogos encontrados nos países africanos, optamos pelo yoté. Popular em países como Senegal, Guiné e Gâmbia, o yoté é utilizado para diversão, apostas e até solução de conflitos nesses locais. Algumas estratégias são criadas e preservadas dentro de cada família e transmitidas de geração em geração (MULLER, 2013). A figura 1 a seguir mostra um exemplar do tabuleiro do jogo: 
Figura 1 - Exemplo do tabuleiro do jogo Yoté

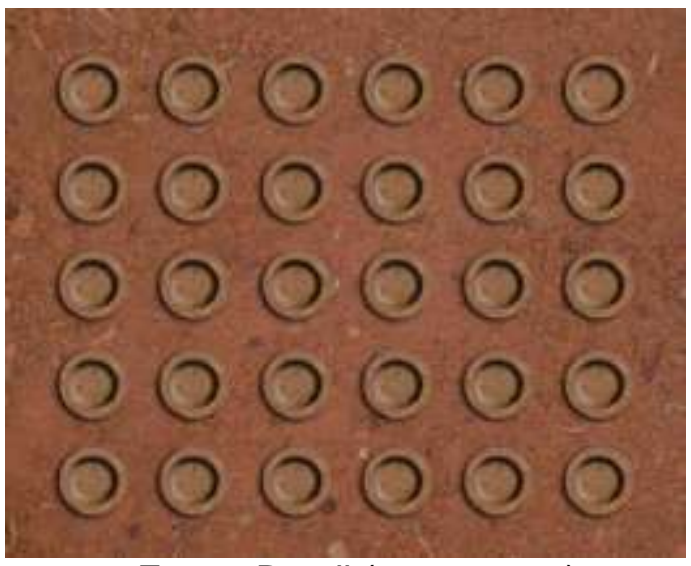

Fonte: Brasil (2010, p. 14)

Similar a Dama, o yoté é formado por um tabuleiro com 30 casas e 12 peças por jogador e tem como objetivo capturar ou bloquear todas as peças do oponente. No quadro 1 a seguir sintetizamos as regras do jogo yoté:

Quadro 1 - Procedimentos do jogo yoté

1) O tabuleiro inicia vazio. Por sorteio, um dos jogadores pode inserir uma peça em qualquer uma das casas. Posteriormente, o jogador oponente faz o mesmo.

2) A partir da segunda rodada, os jogadores podem optar ou por inserir uma nova peça no tabuleiro ou movimentar uma peça já colocada.

3) As peças podem ser movimentadas uma casa por vez na vertical ou horizontal.

4) A captura de uma peça do oponente se dá quando as peças estão lado a lado na vertical ou horizontal, saltando a peça capturada e caindo na casa vazia posterior a essa peça perdida pelo adversário.

5) Para cada captura, retira-se uma segunda peça qualquer do jogador oponente.

6) Vence o jogo quem conseguir capturar ou bloquear o movimento de todas as peças do oponente. Se os dois jogadores bloquearem suas peças mutualmente, vence quem tiver mais peças no tabuleiro.

Fonte: Acervo dos autores

- $\quad$ Por convenção, cada casa do tabuleiro será um quadrado de dimensões 5 $\mathrm{cm} \times 5 \mathrm{~cm}$ e as peças sempre serão colocas no centro do quadrado.

- $\quad \mathrm{Na}$ adaptação do material didático proposto por Brasil (2010), cada peça representa um personagem da história afro-brasileira. Para inserção de cada peça 
no tabuleiro (procedimentos 1 e 2, do quadro 1), os jogadores deverão falar sobre o indivíduo retratado na peça a ser colocada no jogo. Cabe ao oponente validar ou não as informações.

- $\quad$ Para que a captura de uma peça seja realizada (procedimento 4, do quadro 1), o jogador é desafiado pelo adversário a calcular a área de um polígono qualquer formado por até 4 peças.

- Para que tenha direito a retirar uma peça extra após a captura (procedimento 5 , do quadro 1), o jogador é desafiado pelo adversário a calcular o perímetro de um polígono qualquer formado por até $\mathbf{4}$ peças.

Na seção a seguir, apresentaremos o contexto e o percurso metodológico da pesquisa.

\section{Aspectos Metodológicos}

Esta pesquisa se constituiu como uma intervenção pedagógica. Segundo Damiani et al (2013, p. 58), esse tipo de investigação envolve "[...] o planejamento e a implementação de interferências (mudanças, inovações) - destinadas a produzir avanços, melhorias, nos processos de aprendizagem dos sujeitos que delas participam - e a posterior avaliação dos efeitos dessas interferências".

No que se refere aos sujeitos, tivemos como participantes 16 (dezesseis) alunos da disciplina de Laboratório de Práticas Pedagógicas II, do curso de Licenciatura Interdisciplinar em Ciências Naturais e Matemática ${ }^{2}$, na Universidade Federal do Cariri, campus Brejo Santo-CE.

Em relação aos instrumentos de coleta de dados, utilizamos a observação

${ }^{2} \mathrm{O}$ referido curso é a primeira parte de uma formação de dois ciclos oferecida na UFCA. Ofertado em regime integral e com tempo médio de 6 (seis) semestres, o curso habilita seu egresso a lecionar nos anos finais do Ensino Fundamental (6ำ ao 9o ano) nas disciplinas de Ciências e de Matemática. No segundo ciclo formativo, que tem duração média de 3 (três) semestres e é ofertado em turno único, os alunos optam por uma das 4 (quatro) licenciaturas específicas (Química, Biologia, Física ou Matemática) e estarão, ao final desse ciclo, aptos a lecionar no Ensino Médio em suas respectivas áreas de formação específica. 
participante e o questionário misto.

Para o uso da observação, optamos pela perspectiva de observação participante, aqui entendida como técnica em que o investigador imerge no contexto para interagir e vivenciar junto com os sujeitos da pesquisa as situações objeto do estudo (ALVES-MAZZOTTI; GEWANDSZNAJDER, 2000). Esse instrumento foi empregado pelos pesquisadores desse estudo e materializado na forma de um diário de campo.

Além disso, foi utilizado para a coleta de dados o questionário, entendido por Gil (2002, p.128) como um instrumento investigativo formado por questões escritas "[...] tendo por objetivo o conhecimento de opiniões, crenças, sentimentos, interesses, expectativas, situações vivenciadas etc."

Em particular, foram aplicados ao final de cada uma das duas aulas ocorridas durante a intervenção pedagógica um questionário, com o intuito de entender a opinião dos participantes da pesquisa acerca do uso de jogos no ensino de matemática e de avaliar a experiência de utilização do yoté durante a intervenção.

Para organização dados todas as informações obtidas a partir dos instrumentos acima descritos foram cruzadas e dispostas em função da ordem cronológicas dos acontecimentos durante a intervenção pedagógica.

Em relação a análise dos dados, foram empregados os procedimentos de análise quantitativa da recorrência de palavras utilizadas pelos respondentes dos questionários (FREITAS; JANISSEK, 2000); ou a análise qualitativa das respostas (BARDIN, 1994). Ambos os processos desencadearam a discussão dos dados a partir das seguintes categorias emergentes: perspectiva dos alunos em relação ao uso de jogos no ensino de matemática e a opinião desses discentes em relação ao jogo yoté como um como recurso didático. As unidades de análise estabelecidas serão discutidas na seção seguinte. 


\section{A inserção do Yoté na formação dos professores}

A intervenção pedagógica ocorreu em dois momentos da disciplina Laboratório de Práticas Pedagógicas ${ }^{3}{ }^{3}$, nos dias 01/09/2016 e 08/09/2016.

O primeiro encontro iniciou com a discussão sobre a ludicidade no ensino de matemática, com enfoque na importância do lúdico e jogos para a aprendizagem. Posteriormente ocorreu uma explanação do yoté, evidenciando sua origem e regras, e da história de alguns personagens afro-brasileiros que foram representados posteriormente nas peças do jogo.

Indagados através de um questionário sobre sua opinião em relação ao uso de jogos como recursos didáticos, os respondentes foram unânimes em destacar o caráter promissor dos jogos como ferramentas para o ensino e aprendizagem em matemática.

De modo particular, os participantes presentes destacaram os benefícios desse recurso para o processo de ensino e aprendizagem e/ou ressaltaram a importância da adequação dos jogos aos objetivos previamente estabelecidos. $A$ seguir apresentamos dois exemplos representativos de respostas dos licenciandos segundo as subcategorias acima descritas:

Aluno J.P - É uma ferramenta que auxilia na aprendizagem de maneira lúdica, deixando essa atividade mais prazerosa.

Aluno A.F - O jogo é uma grande ferramenta de ensino, uma vez que, o professor saiba trabalhar este recurso didático em sala de aula, levando os alunos aprenderem brincando de forma prazerosa.

Como podemos notar, ambas as respostas destacadas evidenciam as

3 A referida disciplina é ofertada regularmente no $2^{\circ}$ semestre da Licenciatura Interdisciplinar em Ciências Naturais e Matemática e tem carga horária de 96 horas. Compõe o rol de atividades do curso com enfoque na prática como componente curricular. 
potencialidades dos jogos no ensino e aprendizagem de matemática, mas um dos subgrupos ressalva a importância do professor para o uso adequado dessa ferramenta. Isso corrobora com o argumento de Fiorentini e Miorim (1990, p. 6), que afirmam que:

O professor não pode subjugar sua metodologia de ensino a algum tipo de material porque ele é atraente ou lúdico. Nenhum material é válido por si só. Os materiais e seu emprego sempre devem estar em segundo plano. A simples introdução de jogos ou atividades no ensino da matemática não garante uma melhor aprendizagem dessa disciplina.

Os futuros professores foram questionados ainda sobre as vantagens e desvantagens dos jogos para o ensino e aprendizagem de matemática.

No que se refere aos argumentos utilizados pelos licenciandos sobre as vantagens, classificamos em três subcategorias, a saber: lúdico e dinâmico; formação de competências, habilidades e atitudes; e facilitador do ensino e da aprendizagem.

Cada uma das 16 (dezesseis) respostas foi analisada visando identificar a presença de palavras que caracterizassem cada subcategoria. Verificamos a recorrência de 53 termos nas respostas dos participantes da pesquisa. No quadro 2 a seguir apresentamos o percentual de recorrência (em relação ao total) e as ideias-chave relacionadas a cada uma das subcategorias:

Quadro 2 - Vantagens dos jogos segundo os participantes

\begin{tabular}{|c|c|c|}
\hline SUBCATEGORIAS & IDEIAS-CHAVE & RECORRÉNCIA \\
\hline Lúdico e dinâmico & Prazeroso, divertido, motivador, atrativo, aprender & $34 \%$ \\
\hline $\begin{array}{c}\text { jogando, dinâmico, prático. } \\
\text { competêña de } \\
\text { habilidades e } \\
\text { atitudes }\end{array}$ & $\begin{array}{c}\text { Desenvolve competências, desenvolve habilidades, } \\
\text { estimula construção de estratégias, desenvolve o } \\
\text { raciocínio lógico, estimula o senso crítico promove } \\
\text { interação, estimula participação, ensina regras, } \\
\text { estimula competição, trabalha capacidade de ganhar e } \\
\text { perder. }\end{array}$ & $34 \%$ \\
\hline $\begin{array}{c}\text { Facilitador do } \\
\text { ensino e da } \\
\text { aprendizagem }\end{array}$ & $\begin{array}{c}\text { Amplia aprendizado, capta atenção, vontade de } \\
\text { aprender, desperta interesse, melhora absorção, } \\
\text { melhora desempenho, recurso facilitador, melhora } \\
\text { aproveitamento, desmistifica a Matemática, facilita a } \\
\text { absorção, melhora o repasse. }\end{array}$ & $32 \%$ \\
\hline
\end{tabular}

Fonte: Acervo dos pesquisadores

Observamos que as principais vantagens acerca do uso de jogos no ensino 
e aprendizagem de matemática segundo os participantes da pesquisa possuem recorrência semelhante. $O$ que sugere que as potencialidades destacadas são vistas com a mesma importância pelos respondentes.

Em relação as opiniões dos discentes sobre as desvantagens que os jogos podem trazer para o ensino e aprendizagem de matemática, relacionamos a duas subcategorias, são elas: fugir dos objetivos de ensino; e gerar problemas comportamentais.

De modo similar a análise das vantagens do jogos segundo os participantes, identificamos nas respostas dadas a ocorrência de 33 termos que remetiam as subcategorias propostas. A seguir, o quadro 3 apresenta essas subcategorias, suas respectivas porcentagens arredondadas e ideias-chave relacionadas:

Quadro 3 - Desvantagens dos jogos segundo os participantes

\begin{tabular}{|c|c|c|}
\hline SUBCATEGORIAS & IDEIAS-CHAVE & RECORRÉNCIA \\
\hline $\begin{array}{l}\text { Gerar problemas } \\
\text { comportamentais }\end{array}$ & $\begin{array}{c}\text { Acomodação do professor, desinteresse pelo jogo, } \\
\text { perda de foco, dispersar, fugir do foco, perder de foco } \\
\text { no conteúdo, desprendimento da atenção, indisciplina, } \\
\text { bagunça, perder o controle, competição, briga, } \\
\text { estimular a competitividade, gerar ambiente } \\
\text { desarmonioso, gerar rivalidade, falta de espírito } \\
\text { esportivo, necessidade de lidar com sentimento de } \\
\text { perda para evitar conflitos, não participação pela } \\
\text { timidez. }\end{array}$ & $73 \%$ \\
\hline $\begin{array}{l}\text { Fugir dos objetivos } \\
\text { de ensino }\end{array}$ & $\begin{array}{l}\text { Passatempo, jogo pelo jogo, apenas brincadeira, } \\
\text { apenas diversão, encarar somente como jogo, gasto } \\
\text { excessivo de tempo. }\end{array}$ & $27 \%$ \\
\hline
\end{tabular}

Fonte: Acervo dos pesquisadores

Notamos que os comportamentos inadequados que podem surgir com a utilização do jogo como recurso didático de matemática são as principais desvantagens apontadas futuros professores. Além disso, os licenciandos demonstram ainda preocupação com a mera inserção do jogo com finalidade em si, com enfoque apenas no entretenimento.

Após construção do tabuleiro e peças do yoté em casa, o segundo encontro foi reservado para utilização do jogo em sala de aula.

Para colocar as peças no tabuleiro, os jogadores são requisitados a falar 
sobre o personagem representado. Notamos o envolvimento das equipes na participação da atividade e um trabalho independente, sem solicitar auxílio dos pesquisadores. Porém, quando questionados sobre as dificuldades que tiveram durante a intervenção, cerca de $82 \%$ dos estudantes relataram problemas em aprender as histórias de todos os personagens, o que tornava o início do jogo mais demorado.

Durante o desenvolvimento das atividades observamos ainda dificuldades pontuais em relação ao cálculo das áreas dos polígonos, descrito por $18 \%$ dos participantes como percalço vivenciado durante a intervenção. Essa constatação pelos estudantes pode ter se dado em virtude do esquecimento das fórmulas para o cálculo de áreas de figuras planas e/ou pelo tempo insuficiente da atividade (2 horas).

Incentivados ao final a externar suas opiniões sobre o jogo yoté usado durante a intervenção, $73 \%$ dos participantes ressaltaram a relevância na integração entre conteúdos matemáticos e discussão de elementos da história da cultura afro-brasileira. Logo adiante apresentamos algumas respostas dadas pelos discentes que representam essa perspectiva:

Aluna F.D - É um jogo bastante interessante, ajuda a aprender um pouco sobre a cultura afro e também a calcular área matemática. É uma forma dinâmica de ensinar um assunto tão discriminado, que é a nossa cultura.

Aluno A.B - Interessante; uma forma criativa e interdisciplinar de promover uma prática de ensino, observando temáticas de cunho histórico cultural para a resolução de problemas matemáticos.

Como é possível notar, os alunos ressaltaram a importância do trabalho com o tema relacionado a cultura afro-brasileira e africana como forma de valorizar e reconhecer as raízes do povo brasileiro. Além disso, destacaram o caráter interdisciplinar que o jogo yoté pode assumir, ao integrar temas de disciplinas como História e Matemática. 
Finalizadas as discussões dos resultados, passamos na próxima seção a pontuar algumas considerações sobre a experiência educacional empreendida.

\section{Considerações Finais}

O desenvolvimento de práticas pedagógicas na Educação Básica que contribuam para a formação de atitudes, como a de reconhecimento e valorização da cultura africana e afro-brasileira é um dos desafios que se coloca para os cursos de formação de professores de Matemática no país.

Estudando esse problema, a presente pesquisa discutiu sobre alguns elementos que permearam uma experiência de intervenção educativa com enfoque no ensino de matemática para discentes de um curso de licenciatura em ciências e matemática, a partir da utilização do jogo africano yoté.

Houve unanimidade entre os estudantes no entendimento de que os jogos são ferramentas promissoras para o ensino e aprendizagem de matemática, justificando a partir de argumentos bastante comuns na literatura sobre o tema (por seu caráter lúdico, dinâmico, motivador, por exercitar o raciocínio, entre outros).

Em relação ao uso do jogo yoté, a maioria dos alunos destacou a importância do trabalho integrado entre conceitos matemáticos e elementos da cultura afro-brasileira.

Esses fatos evidenciaram que a discussão no âmbito da formação de professores não deve focar-se apenas na importância ou não do uso de jogos, mas em que aspectos o professor deve considerar quando for inserir esses recursos em suas aulas.

Em relação as vantagens do uso de jogos, os futuros professores atribuíram igual importância para ao jogo como aspecto lúdico e dinâmico; como recurso facilitador; e para desenvolvimento de competências, habilidades e atitudes.

No que se refere às desvantagens, há uma preocupação dos licenciandos 
participantes da pesquisa com a possibilidade de geração de comportamentos inadequados diversos (indisciplina, competitividade excessiva, desatenção, entre outras) durante as aulas e ainda com a utilização do jogo pelo jogo. De modo específico ao uso do yoté, a principal dificuldade encontrada pelos estudantes foi acerca da aprendizagem das histórias dos personagens históricos inseridos na intervenção.

Ambas as observações acima são fundamentais nesse processo de formação dos professores, visto que os licenciandos demonstram em suas colocações preocupações com aspectos importantes para a avaliação dos jogos enquanto recursos didáticos em suas futuras atuações como docentes.

Convém destacar que enquanto uma intervenção pontual, de curta duração e em um contexto educativo específico, as discussões aqui apresentadas devem ser analisadas com cautela, junto com um conjunto maior de investigações com finalidades similares. Apesar dessa limitação, um dos desdobramentos importantes da presente pesquisa é servir como uma referência para o planejamento de novas intervenções em sala de aula, tanto adaptando o yoté para discussão da história de outros personagens (cientistas ou educadores, por exemplo) ou como um modelo para investigação e adaptação de jogos advindos de culturas diversas (como indígenas ou orientais).

O estudo de elementos da cultura afro-brasileira e africana, com enfoque na valorização e reconhecimento desses temas enquanto raízes da cultura brasileira é papel de todas as disciplinas escolares. Portanto, é fundamental que os cursos de licenciaturas empreendam práticas direcionadas não apenas ao conteúdos conceituais e procedimentais de matemática, mas ainda aos conteúdos atitudinais, essenciais para a formação de um cidadão que respeite a diversidade em uma sociedade multicultural.

\section{Referências}

ALVES-MAZZOTTI, A. J.; GEWANDSZNAJDER, F. O método nas ciências naturais e sociais: pesquisa quantitativa e qualitativa. São Paulo: Pioneira, 2000. 
BARDIN, L. Análise de conteúdo. Lisboa: Edições 70, 2 ed., 1994.

BARRETO, G. B. B. O ensino de matemática através de jogos educativos africanos: um estudo de caso em uma turma de educação de jovens e adultos (EJA) de uma escola municipal de Aracaju. 2016. 134f. Dissertação (Mestrado em Ensino de Ciências Naturais e Matemática). Universidade Federal do Sergipe, São Cristóvão, 2016.

BRASIL. Parâmetros curriculares nacionais: Matemática. Brasília: Ministério da Educação, Secretaria de Educação Fundamental, 1998.

Diretrizes Curriculares Nacionais para a Educação das Relações Étnico Raciais e para o Ensino de História e Cultura Afro-Brasileira e Africana. Brasília: Ministério da Educação, Secretaria de Educação Continuada, Alfabetização e Diversidade, 2004.

Lei no 11.645, 10 março de 2008. Altera a Lei no 9.394, de 20 de dezembro de 1996, modificada pela Lei no 10.639, de 9 de janeiro de 2003, que estabelece as diretrizes e bases da educação nacional, para incluir no currículo oficial da rede de ensino a obrigatoriedade da temática "História e Cultura Afro-Brasileira e Indígena". Diário Oficial da República Federativa do Brasil, Poder Executivo, Brasília. 2008. Seção 1, p. 1.

Yoté: o jogo da nossa história. Brasília: Ministério da Educação, Secretaria de

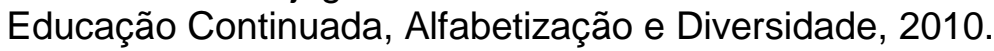

. Brasil no PISA 2015: análises e reflexões sobre o desempenho dos estudantes brasileiros. São Paulo: Fundação Santillana, 2016.

DAMIANI, M. F. et al. Discutindo pesquisas do tipo intervenção pedagógica. Cadernos de Educação, n. 45, p. 57-67, 2013.

FIORENTINI, D.; MIORIM, M. A. Uma reflexão sobre o uso de materiais concretos e jogos no Ensino da Matemática. Boletim da SBEM-SP, v. 4, n. 7, 1990.

FREITAS, H. M. R. de; JANISSEK, R. Análise léxica e análise de conteúdo: técnicas complementares, sequenciais e recorrentes para exploração de dados qualitativos. Porto Alegre: Sagra Luzzatto, 2000.

GIL, A. C. Como elaborar projetos de pesquisa. São Paulo: Atlas, 4 ed. 2002.

GRANDO, R. C. Recursos didáticos na Educação Matemática: jogos e materiais manipulativos. Revista Eletrônica Debates em Educação Científica e Tecnológica, v. 5, n. 02, p. 393-416, 2015.

MULLER, B. C. Uma experiência pedagógica com jogos africanos na formação continuada de professores de Matemática no município de Serra do Espírito Santo.

Revista Eletrônica Debates em Educação Científica e Tecnológica, v. 3, n. 1, p.41-51, 2014. 